\title{
Knowledge and Impact of COVID-I9 on Middle-Aged and Older People Living with HIV in Lima, Peru
}

Journal of the International

Association of Providers of AIDS Care

Volume 20: I-8

(C) The Author(s) 2021

Article reuse guidelines:

sagepub.com/journals-permissions

DOI: $10.1177 / 23259582211056760$

journals.sagepub.com/home/jia

๑SAGE

\author{
Monica M. Diaz 1,2,* (D), Diego M. Cabrera ${ }^{2,3, *}$, Marcela Gil-Zacarias ${ }^{2}$, \\ Valeria Ramirez ${ }^{2}$, Manuel Saavedra ${ }^{2}$, Cesar Cárcamo², Evelyn Hsieh ${ }^{3}$, \\ and Patricia J. Garcia ${ }^{2}$
}

\begin{abstract}
COVID-19 has had an unprecedented worldwide impact, and Peru has had one of the highest COVID-19 case rates despite implementation of an early strict nationwide quarantine. Repercussions on Peru's healthcare system may impact vulnerable populations, particularly people with HIV (PWH). We explored knowledge of COVID-19 and the socioeconomic and health impact of the pandemic among middle-aged and older PWH. A cross-sectional telephone survey was administered to I56 PWH age $\geq 40$ years receiving care in one of two large HIV clinics in Lima, Peru. The majority of PWH (age $52 \pm 7.7$ years, $41 \%$ female, 65\% completed secondary school or less) were knowledgeable regarding COVID-19 symptoms and prevention methods. Nearly half of those employed prior to the pandemic reported job loss. Female sex (unadjusted prevalence ratio [PR] 1.85 [95\%Cl I.27-2.69]), low educational level (PR I.62 [1.06-2.48]) and informal work (PR I.58 [I.06-2.36]) were risk factors for unemployment but not in adjusted models. Increased anxiety was reported in $64 \%$ and stress in $77 \%$. COVID-19 has had a substantial socioeconomic and mental health impact on PWH living in Lima, Peru, particularly those with lower educational levels and informal workers. Efforts are needed to ensure continued medical care and socioeconomic support of PWH in Peru.
\end{abstract}

\section{Keywords \\ COVID-19, HIV, socioeconomic, Peru, Latin America}

Date received: 23 June 202I; revised: 22 September 202I; accepted: 12 October 202I.

\section{Background}

The Coronavirus Disease 2019 (COVID-19) pandemic has had an unprecedented worldwide impact with significant repercussions in the Latin American region. Although Peru ranks $43^{\text {rd }}$ in the world by population size, ${ }^{1}$ it has one of the highest COVID-19 case counts with over 1.7 million reported cases as of April 2021. ${ }^{2}$ The Peruvian government declared a national state of emergency on March 15th, 2020, with a nationwide lockdown implementing strict control over the population's ability to go outdoors (except to purchase food or pick up medications), a nightly curfew, and closure of national borders. ${ }^{3}$ This quarantine helped flatten the curve of infections in the country, but also had a significant impact on non-COVID-19 healthcare availability. ${ }^{4}$

The COVID-19 pandemic has made each step of HIV care challenging, risking the improvements achieved in HIV-related outcomes over the past decade in Peru. ${ }^{5}$ Detection of new cases of HIV has increased largely due to widespread implementation of HIV screening programs in Peru. ${ }^{6}$ However, during the first half of 2020, only 927 new cases of HIV were diagnosed, a drastic decrease compared with an incidence of 8105 new HIV

\footnotetext{
' University of North Carolina at Chapel Hill, Chapel Hill, NC, USA

2 Universidad Peruana Cayetano Heredia, Lima, Peru

${ }^{3}$ Yale University, New Haven, CT, USA

* MMD and DMC have contributed to this work equally and share first coauthorship.
}

\section{Corresponding Author:}

Patricia J. Garcia, Epidemiology, STD, and HIV Unit, School of Public Health and Administration, Universidad Peruana Cayetano Heredia, Lima, Peru. Av.

Honorio Delgado 430, San Martin de Porres, Lima, Perú.

Email: patricia.garcia@upch.pe 
diagnoses reported the year prior, likely reflecting a decline in HIV testing among those at-risk for HIV during the pandemic. ${ }^{6}$

The pandemic has also had a substantial socioeconomic impact on the general population in Peru, particularly among informal workers who make up nearly $70 \%$ of the Peruvian workforce, and who are burdened with unstable incomes and inadequate healthcare coverage. ${ }^{7}$ From May through July 2020, the Peruvian National Institute of Statistics and Informatics (INEI) reported 6 million people had lost their employment. ${ }^{8}$ It is essential to determine the socioeconomic impact that COVID-19 has had on particularly vulnerable populations, such as those who are informally employed and those with lower educational levels, especially among PWH who are known to be at higher risk for medical comorbidities and poor mental health outcomes. ${ }^{9,10}$ Very few studies from the Latin American and Caribbean (LAC) region ${ }^{11,12}$ address the socioeconomic and health impact of the pandemic, or the knowledge of and attitudes towards COVID-19 infection among PWH. We present findings from a study evaluating knowledge regarding COVID-19, and the socioeconomic and health impacts of the pandemic among middle-aged and older PWH from Lima, Peru.

\section{Material and Methods}

\section{Study Design and Population}

We conducted a cross-sectional study between July and August 2020 among PWH receiving routine healthcare at one of two large HIV clinics located in Lima, Peru. All participants previously enrolled in one of two cross-sectional studies (on aging-related musculoskeletal and neurocognitive comorbidities among PWH) were invited to participate. There were no exclusion criteria other than those of the parent studies (age $<40$ years, nationality other than Peruvian nationality). Participants were re-contacted by telephone and invited to participate in the telephone survey.

Table I. Sociodemographic Characteristics of Participants $(N=156)$.

\begin{tabular}{llr}
\hline & $N=156$ & \\
\hline Characteristics & & \\
$\quad$ Age, mean (SD) & 51.9 & $(7.7)$ \\
$\quad$ Male sex, n (\%) & 92 & $(59.0)$ \\
Education level, $\mathrm{n}(\%)$ & & \\
$\quad$ Secondary school or less & $8 \mathrm{I}$ & $(51.9)$ \\
$\quad$ More than secondary school & 75 & $(48.1)$ \\
$\quad$ Employed prior to the pandemic, $\mathrm{n}(\%)$ & $\mathrm{I} I 2$ & $(71.8)$ \\
Employment type & & \\
$\quad$ Professional & 45 & $(40.2)$ \\
$\quad$ Non-professional & 65 & $(58.0)$ \\
$\quad$ Unknown & 2 & $(1.8)$ \\
Level of employment formality, n (\%) & & \\
$\quad$ Formal worker & 68 & $(60.7)$ \\
$\quad$ Informal worker & 41 & $(36.6)$ \\
$\quad$ Unknown & 3 & $(2.7)$ \\
\hline
\end{tabular}

\section{Sources of Data}

Our survey consisted of 34 questions, divided into four sections, adapted from other validated survey studies: ${ }^{13-15}$ (a) knowledge and perceptions of COVID-19 infection, (b) socioeconomic and health impact of the COVID-19 pandemic, (c) COVID-19 infection history and diagnosis, and (d) occupa-

Table 2. Socioeconomic and Health Impact of the COVID-19 Pandemic on Middle-Aged and Older PWH Living in Lima, Peru by Educational Level ${ }^{\mathrm{a}}$.

$\begin{array}{lll}\begin{array}{l}\text { Secondary } \\ \text { school or }\end{array} & \begin{array}{l}\text { Above } \\ \text { secondary }\end{array} & \\ \text { less } & \text { school } & \text { Prevalence } \\ \mathrm{n}(\% \text { Yes }) & n \text { (\% Yes) } & \text { Ratio } \\ n=8 \mathrm{I} & n=75 & (95 \% \mathrm{Cl})^{\mathrm{a}}\end{array}$

Mental and physical health impact of the pandemic or stress or feelings of sadness Increase in sleep problems or poor sleep quality Increase in health $23(28.4) \quad 29(38.7) \quad 0.73(0.47-\mathrm{I}) 15)$
problems unrelated to COVID-19

infection

Decrease in $\quad 53(65.4) \quad 5 I(68.9) \quad 0.95(0.76-1.18)$ physical activity or exercise

Overeating or
eating more $27(33.3) \quad 33(44.6)$

$0.75(0.50-I . I I)$ unhealthy foods

Healthcare and ART access during the pandemic Currently on ART $80(98.8) \quad 72(96.0)$ accessing ART $13(16.1) \quad 24(32.4)$

$1.03(0.98-1.08)$

refills or pick-up

Difficulty

$23(30.0) \quad 35(49.3)$

$0.61(0.40-0.92)$

accessing routine

HIV care ${ }^{b}$

COVID-19 Infection history

Currently or $8(9.9)$

$5(6.7)$

$1.48(0.5 \mathrm{I}-4.33)$

previously

symptomatic but

was not tested for

COVID-19

infection

Tested positive for

$2(3.5)$

$2(4.1)$

$0.86(0.13-5.88)$

COVID-19

infection $^{c}$

Hospital stay due

to COVID-19

infection

Socioeconomic impact of the pandemic

Restricted to those who were employed prior to the pandemic $(n=I I 2$, 7I.8\%)

\begin{tabular}{l}
$\begin{array}{l}\text { Became newly } \\
\text { unemployed }\end{array} \quad 30(58.8) \quad 2 I(34.4) \quad$ I.7I (I.I3-2.59) \\
\hline
\end{tabular}

.

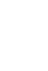


Table 2. (continued)

\begin{tabular}{|c|c|c|c|}
\hline & $\begin{array}{l}\text { Secondary } \\
\text { school or } \\
\text { less } \\
n(\% \text { Yes) } \\
n=81\end{array}$ & $\begin{array}{l}\text { Above } \\
\text { secondary } \\
\text { school } \\
n \text { (\% Yes) } \\
n=75\end{array}$ & $\begin{array}{l}\text { Prevalence } \\
\text { Ratio } \\
(95 \% \mathrm{Cl})^{\mathrm{a}}\end{array}$ \\
\hline Changed jobs & $7(14.0)$ & $8(13.1)$ & $1.07(0.42-2.74)$ \\
\hline $\begin{array}{l}\text { Workload or } \\
\text { work } \\
\text { responsibilities } \\
\text { increased }\end{array}$ & $15(30.0)$ & $36(59.0)$ & $0.51(0.32-0.82)$ \\
\hline $\begin{array}{l}\text { Work exposure } \\
\text { to the general } \\
\text { public during the } \\
\text { pandemic }\end{array}$ & $23(46.0)$ & $21(34.4)$ & $\mathrm{I} .34(0.84-2.1 \mathrm{I})$ \\
\hline
\end{tabular}

Abbreviations: $\mathrm{ART}=$ antiretroviral therapy; $\mathrm{PWH}=$ persons with HIV. Prevalence ratios associated with $\mathrm{p}$ values $<0.05$ appear in boldface.

${ }^{a}$ Reference group $=$ above secondary school.

bercentages calculated of 148 participants who attempted to access routine HIV clinical care during the pandemic; $n=77$, secondary school or less; $n=7$ I, above secondary school.

'Data available for $n=106 ; n=57$, secondary school or less; $n=49$, above secondary school. Data was not collected on the number of participants who had a COVID-19 test.

tion and employment history (Supplementary Table I). Questions were translated from English into Spanish by two fully bilingual investigators (MMD, DMC), and were corroborated by two native Spanish-speaker study team members (VR, MS). For all patients, demographic information (age, sex, educational level, district of residence) was obtained from their prior project records with their consent.

\section{Data Analysis}

Means and standard deviations were used to report descriptive statistics of continuous variables and frequencies and percentages for categorical variables. Univariate and multivariable (adjusted for relevant covariates, such as sex, educational level and/or occupation type) were performed using generalized linear model with family Poisson and link log to calculate prevalence ratios (PR) and their corresponding 95\% confidence intervals $(95 \% \mathrm{CI})$. All variables that were significant in the univariate analyses were included as covariates in the multivariable analyses. Statistical analyses were performed using STATA (College Station, TX, USA) and JMP Pro version 14.2.0 (Cary, NC, USA).

\section{Ethical Approval and Informed Consent}

This study was reviewed and approved by the ethics committees of the Universidad Peruana Cayetano Heredia (Reference number 202113), Via Libre (Reference number 5880) and Yale School of Medicine (Reference number MODCR00005834) institutional review boards. All participants enrolled in this study provided verbal informed consent after a comprehensive explanation of the procedures by phone prior to study enrollment.

\section{Results \\ Sociodemographic and Clinical Characteristics}

A total of 293 eligible PWH were approached for study enrollment consideration. Of these, 98 participants could not be reached by phone (ie non-functioning phone number, no response to multiple calls), one participant was deceased. 38 of the 194 participants contacted $(19.6 \%)$ declined to participate. Of the $156 \mathrm{PWH}$ who consented to participate in the study, the average age was $52 \pm 7.7$ years and $41 \%$ were female. Eleven \% completed up to primary school, 54\% more than primary school but up to secondary school, and $35 \%$ completed above secondary school. Around $72 \%$ of the participants were employed prior to the pandemic; of these, $36.6 \%$ reported being in the informal sector (Table 1).

More than $10 \%$ of patients reported symptoms of COVID-19, but only four participants reported testing positive for COVID-19 infection, and no one with self-reported infection reported hospitalization (Table 2). No differences in COVID-19 infection rates were observed by educational level $(P=.746)$ or employment type (formal vs informal work, $P=$ $.824)$.

\section{Knowledge of COVID-19 Infection}

The majority of all participants correctly answered that the most efficacious prevention methods against COVID-19 infection were wearing a facial mask (96\%), frequent handwashing (99\%), avoiding close contact with people who are sick (96\%) and avoiding touching the face (97\%). Nearly half (46.8\%) of participants believed gargling salt water would prevent COVID-19 transmission and 22.4\% believed taking antibiotics was helpful. A significantly higher proportion of participants with lower educational levels (32.1\%) believed that taking antibiotics would prevent COVID-19 transmission compared to those with higher educational levels $(P=.003)$. The majority of participants correctly identified signs or symptoms related to COVID-19 infection, including cough (89.7\%), fever (98.7\%), shortness of breath $(99.4 \%)$; data not shown. Symptoms such as nosebleeds $(8.3 \%)$ and skin rash $(18 \%)$ were incorrectly identified as symptoms of COVID-19 infection.

\section{Socioeconomic Impact of COVID-19}

Around $70 \%$ of the participants were employed prior to the pandemic. Around $46 \%$ reported being laid off from their jobs during the pandemic and nearly $40 \%$ did not follow the recommendations for telework and continued to work in close contact with the public (Table 2 ). Nearly one-half (51/112) reported an increase in their workload or work responsibilities. Two-thirds of those with lower educational levels became newly 
Journal of the International Association of Providers of AIDS Care

unemployed during the pandemic, significantly more than those with higher educational levels $(58.8 \%$ vs $34.4 \%, P=.010$; Table 2). Those with higher educational levels had significantly greater workload or work responsibilities during the pandemic compared with lower education levels $(59 \%$ vs $30 \%, P=$ .002 ; Table 2). In unadjusted regression analyses, female sex was a risk factor for job loss during the pandemic [PR 1.85 [95\%CI 1.27-2.69], as were lower educational levels [PR 1.62 [95\%CI 1.06-2.48]], but this was not statistically significant in adjusted models. Having informal employment was an independent risk factor for unemployment during the pandemic [PR 1.58 [95\%CI 1.06-2.36]], but not in the adjusted analyses [Table 3].

\section{Mental Health Impact of the COVID-I 9 Pandemic}

A majority of patients in our study expressed an increase in anxiety (64\%) and stress (77\%) since the beginning of the pandemic. Older age ( $\geq 50$ years) and being newly unemployed during the pandemic significantly increased risk of new mental health problems in univariate analyses (PR 0.89 [CI $0.80-0.99$ ] and PR 1.16 [1.03-1.31], respectively) but not in multivariable analyses (Table 3 ). There were no other significant trends related to increases in mental health symptoms. Lower education levels and employment type did not significantly increase risk of new or worse mental health symptoms during the pandemic ( $P>.05$ for both). Of those who had new or worse mental health symptoms during the pandemic $(n=139), 60(43.3 \%)$ sought mental health treatment or therapy, and $43.3 \%$ had difficulty accessing mental health care during the height of the pandemic with no difference by educational level $(P=.113)$ (Table 2$)$.

\section{Physical Health Impact of the COVID-19 Pandemic}

Overall, one-third of the cohort reported an increase in health problems unrelated to COVID since the beginning of the pandemic, with no significant differences by educational level $(P$ $=.174$; Table 2 ). A majority of the cohort reported decreased physical activity or exercise $(66.7 \%)$ with no significant differences between men and women $(P=.818$ and $P=.561$, respectively) and no differences by educational level (Table 2). Older age was not a significant predictor of decreased physical activity $(P=.060)$. Nearly $40 \%$ reported an increase in overeating or eating unhealthy foods with more men $(45.6 \%)$ compared with women $(28.1 \%)$ reporting this $(P=.05)$. Educational level and employment type were not associated with unhealthy eating habits $(P>.05)$.

\section{HIV Care During the COVID-19 Pandemic}

Nearly all participants $(97 \%)$ reported continuing to regularly take their ART medication, despite nearly one-quarter of the cohort (24\%) reporting difficulty picking up their ART (Table 2). Of those who either were no longer taking their ART or had difficulty accessing ART refills $(n=37)$, the most common reason was because of cancelled clinic appointments $(26 \%)$, difficulty communicating with the HIV clinic $(21 \%)$ or a lack of transportation to pick-up medications (21\%). More than one-third (37.2\%) reported having difficulty accessing their routine HIV medical care (Table 2), and the most common reason was that their primary HIV clinic was temporarily closed during the pandemic (46.6\% [27/58]; data not shown).

\section{Discussion}

Peru has had one of the highest incidences of COVID-19 despite its early nationwide quarantine. Most 'non-essential' activities were suspended throughout the duration of the quarantine for nearly four months, but Peru still remains in a state of emergency with slow reactivation of the economy as of September 2021, just coming out from a second wave of cases. ${ }^{16,17}$ The closure of many outpatient clinics has meant that persons with chronic medical conditions requiring regular clinical care and access to life-long treatment, such as PWH, may be at increased risk for negative outcomes if their treatment is interrupted. Our study showed that most of the participants were knowledgeable in identifying correct COVID-19 infection prevention methods and COVID-19-related symptoms. We also found that the pandemic has had a large socioeconomic impact among PWH reporting significant job loss, physical and mental health burden and difficulty accessing routine HIV care or ART during the height of the pandemic.

\section{Knowledge of COVID-19 Infection}

Prior studies have shown that knowledge of infection transmission and behaviors related to COVID-19 could be importantly influenced by education level. ${ }^{18}$ One study of 225 Peruvians, mostly with university degrees, found that more than $90 \%$ of the participants could correctly identify COVID-19 symptoms and the majority were knowledgeable of how COVID-19 was transmitted. ${ }^{19}$ Another study of 314 Peruvian pre- or postgraduate university students found also that more than $90 \%$ were able to correctly identify symptoms and transmission routes of COVID-19 infection. ${ }^{20}$ These findings are similar to those we found in our study, possibly associated also with the higher educational levels from our participants. Notably, these studies (including ours) were conducted in populations that are not representative of the mean educational level of the Peruvian general population. ${ }^{21}$

\section{Mental Health Considerations and Socioeconomic Impact}

The mandatory quarantines may lead to increased feelings of isolation in a group of persons who may already be vulnerable to poor mental health outcomes. In two studies of the general US population, ${ }^{22,23} 40 \%$ of adults reported struggling with a mental health concern or substance use since the onset of the 
Table 3. Generalized Linear Models (Unadjusted) for Risk Factors for new Unemployment, Mental and Physical Health Changes During the Pandemic $(N=156)$.

\begin{tabular}{|c|c|c|c|}
\hline & $\begin{array}{l}\text { Newly unemployed during } \\
\text { pandemic } \\
\text { Yes, } n=5 \text { I (45.5\%) }\end{array}$ & $\begin{array}{l}\text { New or worse mental health } \\
\text { symptoms } \\
\text { Yes, } n=139(89.1 \%)\end{array}$ & $\begin{array}{l}\text { Negative physical health } \\
\text { symptoms } \\
\text { Yes, } n=52(33.3 \%)\end{array}$ \\
\hline Characteristic & $\begin{array}{l}\text { Unadjusted Prevalence } \\
\text { Ratio }(95 \% \mathrm{Cl})\end{array}$ & $\begin{array}{l}\text { Unadjusted Prevalence } \\
\text { Ratio }(95 \% \mathrm{Cl})\end{array}$ & $\begin{array}{l}\text { Unadjusted Prevalence } \\
\text { Ratio }(95 \% \mathrm{Cl})\end{array}$ \\
\hline$\geq$ Age 50 years & $1.25(0.82-1.90)$ & $0.89(0.80-0.99)^{*}$ & $\mathrm{I} .43(0.88-2.32)$ \\
\hline Female sex & $1.85(1.27-2.69)^{¥}$ & $1.09(0.98-1.22)$ & $1.05(0.67-1.65)$ \\
\hline $\begin{array}{l}\text { Educational level, Secondary school } \\
\text { or less }\end{array}$ & $1.62(1.06-2.48)^{*}$ & $1.05(0.94-1.18)$ & $0.73(0.47-1.15)$ \\
\hline Profession type, Non-professional & I.4I (0.89-2.22) & $0.89(0.78-1.00)$ & $0.88(0.50-1.54)$ \\
\hline Occupation Type, Informal worker & $1.58(1.06-2.36)^{*}$ & $0.94(0.81-1.08)$ & $0.62(0.32-1.20)$ \\
\hline $\begin{array}{l}\text { Newly unemployed during the } \\
\text { pandemic }\end{array}$ & N/A & $1.16(1.03-1.31)^{*}$ & $1.74(0.94-3.25)$ \\
\hline
\end{tabular}

$* P<.05 ; \stackrel{*}{*}<<.001$.

${ }^{a}$ Employed prior to the pandemic, $n=112$ (71.8\%).

${ }^{\mathrm{b}} \mathrm{New}$ anxiety or stress or feelings of sadness since March I5, 2020.

pandemic. Anxiety symptoms during the pandemic were three times higher $(25.5 \%$ vs $8.1 \%)$ and the prevalence of depressive symptoms, four times that reported in the second quarter of $2019(24.3 \%$ vs $6.5 \%))^{22}$ One study of 1699 questionnaires administered to Peruvians between April and September 2020 found that psychological distress was particularly high in women, young people and those with lower educational levels, highlighting some populations susceptible to negative mental health outcomes during the pandemic. ${ }^{24}$ Our study identified PWH as another important population in where mental health has been affected negatively during this period and requires further attention, such as an increase in mental health services for older Peruvians with HIV.

Socioeconomic challenges due to the pandemic, such as job loss or increased workload, may also create new mental health challenges or exacerbate pre-existing ones. One survey of 1200 Peruvians in the general population published in February 2021 found that $36.6 \%$ had lost their employment since the beginning of the pandemic, ${ }^{25}$ and in another study, 3 out of 10 people lost their jobs in Peru. ${ }^{26}$ Moreover, another study found that $70 \%$ of Peruvians were unable to transition work to home. ${ }^{27}$ One international study ${ }^{12}$ with a majority of participants from LAC (17\% of the cohort were PWH) found that $11 \%$ of all participants lost their employment as a result of changes due to the pandemic, and of those who became newly unemployed, $50 \%$ had depression and $48 \%$ anxiety. Notably, men living with HIV were more likely to report expected income reductions during the pandemic compared to those without HIV (46\% vs 36\%; $P=.01) .{ }^{12}$ The National Institute of Statistics from Peru reported for 2019 , that $85.8 \%$ of Peruvians between 50 to 59 years of age were economically active, in either formal or informal jobs. ${ }^{28}$ The baseline employment rate in our study was $71 \%$, much lower than from general population of the same age. Adding to that gap, between the onset of the pandemic and September 2020 nearly half (45.5\%) lost their employment, highlighting the huge socioeconomic impact that the lock-down and pandemic has had on older PWH in Lima, Peru.

During the pandemic, 1 in 3 Peruvians reported anxiety or depression symptoms and 144000 Peruvians accessed mental health services from the beginning of the pandemic until July $2020 .^{29}$ A study among 247 Peruvian older adults, determined that factors such as being a woman and having had a diagnosis of COVID-19 (either themselves or a family member) were statistically associated with anxiety and depression. ${ }^{30} \mathrm{PWH}$ are known to be at higher risk of experiencing social isolation due to stigma and fear of rejection. ${ }^{31-33}$ Among Peruvian $\mathrm{PWH}$, an elevated prevalence of depression $(48 \%-68 \%)$ has been reported, ${ }^{9,34}$ and more than $50 \%$ of Peruvian PWH have perceived some form of stigma or rejection associated with social isolation. ${ }^{35}$ It is likely that the contributions of older age, living with a chronic condition such as HIV, the lock-downs plus the socioeconomic impacts of the pandemic resulted in poor mental health outcomes in PWH, as reflected in our study in which more than two-thirds of the participants reported anxiety and almost $80 \%$ more stress compared with prior to the pandemic.

Access to mental health services is crucial, particularly for $\mathrm{PWH}$, during this period, however the implementation of mental health services has been challenging. ${ }^{36} \mathrm{We}$ found that nearly $40 \%$ of our study participants attempted to access these services at some point during the pandemic and about half of them had access difficulties. In one study of mental health decision-makers of ministries of health of 10 South American countries, including Peru, national lockdowns were identified as a primary barrier to delivery and access to mental health services during the pandemic. ${ }^{37}$ However, in order to address such barriers, some institutions such as the AIDS Healthcare Foundation, ${ }^{38}$ have set up access to online telehealth visits with a mental health provider. ${ }^{39}$ Innovation in mental health services during the pandemic is crucial to help mitigate the psychological effects of the pandemic. 


\section{Challenges to Continuity of HIV Care During the Pandemic}

In Peru, among the estimated $72000 \mathrm{PWH}, 64 \%$ had been diagnosed, $46 \%$ were on ART, and $36 \%$ had achieved viral suppression. ${ }^{40}$ HIV medications are supplied and provided for free to all PWH by the Peruvian Ministry of Health. However, the challenges of maintaining or improving these figures could worsen during the COVID-19 pandemic due to the re-allocation of health resources previously directed toward funding HIV care toward the inpatient care of patients with COVID-19. In order to ensure medical care of PWH during a quarantine, sufficient and steady ART supplies at health care centers must be available to achieve optimal ART adherence. ${ }^{41}$ However, while longer ART refills would help ensure continuous ART adherence, it also reduces the opportunity for clinical interactions with an HIV health care provider, including medication adherence counseling and viral load testing. In our study, nearly one-quarter of the group had difficulty accessing their ART during the study period and close to half reported difficulty accessing routine HIV care. Despite this, most of the participants reported compliance with ART during the pandemic, which could be related to changes the Ministry of Health implemented offering 3-month ART supplies and ART home delivery to patients who could not pick them up in the HIV clinics. ${ }^{42}$

Telemedicine implementation has been tried for continuity of care of PWH during the quarantine facilitating ART initiation and monitoring. However, barriers to implementation throughout much of Peru, including lack of consistent access to internet services and lack of equipment for telemedicine within clinics, make this reality difficult to achieve. ${ }^{43}$ In one of the clinic site where the study took place, telemedicine was implemented as a means to reach PWH to reduce their risk of exposure to COVID-19. Strategizing ways ensure a steady ART supply and ART delivery to patients, and stable access to clinical care during the pandemic is fundamental to avoid an increase in HIV multimorbidity, overburdening hospitals and subsequently increasing morbidity of the general population.

Our study has limitations. First, this study was a crosssectional telephone survey and did not have an HIV-negative control group for comparison. However, national surveys of the general Peruvian population allowed us to make comparisons to the findings of PWH in our study. ${ }^{25,27,29}$ Second, this was a convenience sample of middle-aged to older PWH attending two large multidisciplinary HIV clinics in an urban capital city, thus, may not be representative of all Peruvian PWH. Third, our sample was largely educated with the majority of participants having completed secondary school, exceeding the proportion of Peruvians with at least some secondary schooling (64\% female, $75.4 \%$ male). ${ }^{21}$ Next, most women were recruited from one of the study sites, but despite these recruitment differences, PWH did not differ greatly between study sites. On the other hand, although there have been some surveys exploring knowledge and socioeconomic, physical and mental health impacts of the pandemic in general population, ${ }^{25,27}$ this is the first one exploring these areas in PWH in Peru.

Our data has shown that the COVID-19 pandemic and measures taken to reduce its transmission have posed a significant mental health and socioeconomic burden on Peruvian PWH and may pose a considerable burden upon PWH in other low-to-middle income countries. As Peru enacted policies to slow the spread of COVID-19 through quarantines and shutdown of most non-essential establishments early on in the beginning of the pandemic, ${ }^{4}$ these measures may inadvertently have negative consequences on vulnerable populations including those with HIV. These early struggles of HIV clinics in providing continued healthcare to their patients have led some clinics to develop a systematic approach to mail delivery of ART and provision of telemedicine consults, however, this is not yet standardized across much of Peru. Further efforts are needed to ensure that PWH on ART can obtain routine HIV care without increased COVID exposure by ramping up access to telehealth and ART home delivery systems. It is also crucial for those newly diagnosed with HIV during the pandemic to be linked to HIV care and treatment in a timely manner. Finally, the increase in perceived anxiety, stress and depressive symptoms observed among older PWH in our study underscores the importance of strengthening mental health resources and access via telemedicine for this vulnerable population.

\section{Acknowledgments}

The authors would like to thank the HIV clinics from which participant recruitment and enrollment took place.

\section{Declaration of Conflicting Interests}

The author(s) declared no potential conflicts of interest with respect to the research, authorship, and/or publication of this article.

\section{Funding}

Dr Monica M. Diaz serves as a Fogarty Global Health Trainee and is supported by the FIC at the NIH under grant number D43TW009343 and is also supported by the Alzheimer's Disease Resource Center for advancing Minority Aging Research at the University of California San Diego (P30AG059299, National Institute on Aging). Dr Diego M. Cabrera serves as a Fogarty Global Health Trainee and is supported by the Fogarty International Center (FIC) at the National Institutes of Health (NIH) and the National Institute of Arthritis and Musculoskeletal and Skin Diseases (NIAMS) under grant number D43TW010540. Dr Hsieh is supported by NIH/Fogarty International Center K01TW009995. The content is solely the responsibility of the authors and does not necessarily represent the official views of the NIH.

\section{Disclosures}

MMD has no disclosures to report. DMC has no disclosures to report. MG has no disclosures to report. VR has no disclosures to report. MS has no disclosures to report. PJG has no disclosures to report. EH has no disclosures to report. 


\section{Funding}

The author(s) disclosed receipt of the following financial support for the research, authorship, and/or publication of this article: This work was supported by the Fogarty International Center (grant number D43TW009343, D43TW010540, K01TW009995, P30AG059299).

\section{ORCID iD}

Monica M. Diaz (D) https://orcid.org/0000-0001-9663-5948

\section{Supplemental Material}

Supplemental material for this article is available online.

\section{References}

1. Peru Population. 2020. Worldometer. Accessed August 21, 2020. https://www.worldometers.info/world-population/peru-pop ulation/

2. COVID-19 Map. Johns Hopkins Coronavirus Resource Center. Accessed July 18, 2020. https://coronavirus.jhu.edu/map.html

3. Garcia PJ, Alarcón A, Bayer A, et al. COVID-19 Response in latin america. Am J Trop Med Hyg. 2020;103(5):1765-1772. doi:10. 4269/ajtmh.20-0765

4. Peru Ministerio de Salud. Resolucion Ministerial. No. 95-2020MINSA. Lima, 18 marzo 2020.

5. Jiang $\mathrm{H}$, Zhou $\mathrm{Y}$, Tang W. Maintaining HIV care during the COVID-19 pandemic. Lancet HIV. 2020;7(5):e308-e309. doi:10.1016/S2352-3018(20)30105-3

6. Centro Nacional de Epidemiologia. Prevención y Control de Enfermedades - MINSA. Sala situacional VIH/SIDA, CDC Perú. Sala situacional VIH/SIDA, CDC Perú. Accessed July 13, 2020. https://www.dge.gob.pe/vih/sala/index/fig1_Curvavih/22

7. Salazar-Xirinachs JM, Chacaltana J. Politicas de Formalizacion en America Latina: Avances y Desafios. Published 2018. Accessed September 30, 2020. https://www.ilo.org/wcmsp5/groups/public/ —americas/_ro-lima/documents/publication/wcms_645159.pdf

8. La población ocupada del país alcanzó 10 millones 272 mil 400 personas en el II trimestre del 2020, 15/08/2020. Instituto Nacional de Estadistica e Informatica. https://www.inei.gob.pe/ prensa/noticias/la-poblacion-ocupada-del-pais-alcanzo-10-millones272-mil-400-personas-en-el-ii-trimestre-del-2020-12346/

9. Wu DY, Munoz M, Espiritu B, et al. Burden of Depression Among Impoverished HIV-Positive Women in Peru, $J$ Acquir Immune Defic Syndr. 2008;48(4):500-504. doi:10.1097/QAI. $0 \mathrm{~b} 013 \mathrm{e} 31817 \mathrm{dc} 3 \mathrm{e} 9$

10. Joska JA, Andersen L, Rabie S, et al. COVID-19: increased risk to the mental health and safety of women living with HIV in South Africa. AIDS Behav. 2020;24(10):2751-2753. doi:10.1007/ s10461-020-02897-z

11. Torres TS, Hoagland B, Bezerra DRB, et al. Impact of COVID-19 pandemic on sexual minority populations in Brazil: an analysis of social/racial disparities in maintaining social distancing and a description of sexual behavior. AIDS Behav. 2021;25(1):73-84. doi:10.1007/s10461-020-02984-1

12. Santos G-M, Ackerman B, Rao A, et al. Economic, mental health, HIV prevention and HIV treatment impacts of COVID-19 and the COVID-19 response on a global sample of cisgender Gay Men and other Men Who have Sex with Men. AIDS Behav. 2021;25(2):311-321. doi:10.1007/s10461-020-02969-0

13. Zhong B-L, Luo W, Li H-M, et al. Knowledge, attitudes, and practices towards COVID-19 among Chinese residents during the rapid rise period of the COVID-19 outbreak: a quick online crosssectional survey. Int J Biol Sci. 2020;16(10):1745-1752. doi:10. $7150 /$ ijbs. 45221

14. Economía informal en Perú: Vargas V. 2016. Situación actual y perspectivas. Centro Nacional de Planeamiento Estratégico. Accessed September 30, 2020. https://perureports.com/wpcontent/uploads/2016/08/Economia-informal-en-Peru-situacionactual-perspectivas-15-03-2016.pdf

15. Grasso DJ, Briggs-Gowan MJ, Carter AS, Goldstein BL, Ford JD. Profiling COVID-related experiences in the United States with the epidemic-pandemic impacts inventory: linkages to psychosocial functioning. Brain Behav. 2021;11(8):e02197. doi:10.1002/brb3. 2197

16. Decreto Supremo que prorroga la Emergencia Sanitaria declarada por Decreto Supremo N ${ }^{\circ} 008-2020-\mathrm{SA}$, prorrogada por Decretos Supremos $\mathrm{N}^{\circ}$ 020-2020-SA, $\mathrm{N}^{\circ}$ 027-2020-SA y $\mathrm{N}^{\circ}$ 031-2020-SA. https://busquedas.elperuano.pe/normaslegales/decreto-supremo-queprorroga-la-emergencia-sanitaria-declara-decreto-supremo-n-0092021-mina-1929103-4/.

17. Sala Situacional COVID-19 Peru. https://covid19.minsa.gob.pe/ sala_situacional.asp.

18. Alsan M, Stantcheva S, Yang D, Cutler D. Disparities in coronavirus 2019 reported incidence, knowledge, and behavior Among US adults. JAMA Netw Open. 2020;3(6):e2012403. doi:10.1001/ jamanetworkopen.2020.12403

19. Zegarra-Valdivia J, Brenda NCV, Ames-Guerrero RJ. Knowledge, Perception and Attitudes in Regard to COVID-19 Pandemic in Peruvian Population. PsyArXiv. April 16, 2020. doi:10.31234/osf.io/kr9ya

20. Iglesias-Osores S, Saavedra-Camacho J, Acosta-Quiroz J, Córdova-Rojas L, Rafael-Heredia A. Percepción y conocimiento sobre COVID-19: una caracterización a través de encuestas. Revista Del Cuerpo Médico Del HNAAA. 2021;13(4):356-360. https://doi.org/10.35434/rcmhnaaa.2020.134.763

21. INEI, Instituto Nacional de Estadisticas e Informatica. PERÚ: Indicadores del Índice de Desigualdad de Género referidos a participación política, empleo y educación, según departamento, 2018. Published online 2018. Accessed October 29, 2020. https://www.inei.gob.pe/estadisticas/indice-tematico/brechas-degenero-7913/

22. Czeisler MÉ, Lane RI, Petrosky E, et al. Mental health, substance Use, and suicidal ideation during the COVID-19 pandemic United States, June 24-30, 2020. MMWR Morb Mortal Wkly Rep. 2020;69(32):1049-1057. doi: 10.15585/mmwr.mm6932a1

23. Ettman CK, Abdalla SM, Cohen GH, Sampson L, Vivier PM, Galea S. Prevalence of depression symptoms in US adults before and during the COVID-19 pandemic. JAMA Netw Open. 2020;3(9):e2019686. doi:10.1001/jamanetworkopen.2020.19686

24. Ruiz-Frutos C, Palomino-Baldeón JC, Ortega-Moreno M, et al. Effects of the COVID-19 pandemic on mental health in Peru: psychological distress. Healthcare (Basel). 2021;9(6):691. doi:10. 3390/healthcare9060691 
25. CPI, Peru Urbano-Rural: Personas de 18 años a mas de todos los NSE. Impacto de la pandemia. Base: 1200 entrevistados.

26. Peru, Ministerio de la Mujer y Poblaciones Vulnerables. Encuesta sobre percepciones y actitudes de mujeres y hombres frente al aislamiento social obligatorio a consecuencia del COVID-19. https://observatorioviolencia.pe/wp-content/uploads/2020/07/Enc uesta_sobre_percepciones_y_actitudes_COVID-19.pdf

27. La Gestion. El 49\% cree que medidas del Gobierno controlarán parcialmente el Covid-19. https:/gestion.pe/peru/encuesta-datumcoronavirus-peru-covid-19-el-49-cree-que-medidas-del-gobiernocontrolaran-parcialmente-el-covid-19-noticia/

28. Instituto Nacional de Estadística e Informática. Perú: Crecimiento y distribución de la población, 2020. Primeros resultados. libro.pdf (inei.gob.pe).

29. Peru, Ministerio de Salud. 2020 July. https://www.gob.pe/ institucion/minsa/noticias/214647-mina-brindo-mas-de-44-milatenciones-en-los-centros-de-salud-mental-comunitarios-durantela-pandemia/

30. Caycho-Rodríguez T, Tomás JM, Vilca LW, et al. Predictors of mental health during the COVID-19 pandemic in older adults: the role of socio-demographic variables and COVID-19 anxiety. Psychol Health Med. 2021;22:1-13. doi:10.1080/13548506. 2021.1944655

31. Marziali ME, Card KG, McLinden T, Wang L, Trigg J, Hogg RS. Physical distancing in COVID-19 May exacerbate experiences of social isolation among people living with HIV. AIDS Behav. 2020;24(8):2250-2252 2020:2250-2252. doi:10.1007/ s10461-020-02872-8

32. Greene M, Hessol NA, Perissinotto C, et al. Loneliness in older adults living with HIV. AIDS Behav. 2018;22(5):1475-1484. doi:10.1007/s10461-017-1985-1

33. Greysen SR, Horwitz LI, Covinsky KE, Gordon K, Ohl ME, Justice AC. Does social isolation predict hospitalization and mortality Among HIV + and uninfected older veterans? J Am Geriatr Soc. 2013;61(9):1456-1463. doi:10.1111/jgs.12410

34. Shin S, Muñoz M, Espiritu B, et al. Psychosocial impact of poverty on antiretroviral nonadherence Among HIV-TB coinfected patients in Lima, Peru. J Int Assoc Physicians AIDS Care. 2008;7(2):74-81. doi:10.1177/1545109708315326

35. Zafra-Tanaka JH, Ticona-Chavez E. Estigma relacionado a VIH/ SIDA asociado con adherencia al tratamiento antirretroviral en pacientes de un hospital de Lima, perú 2014. Rev Peru Med Exp Salud Publica. 2016;33(4):625. doi:10.17843/rpmesp.2016.334.2544

36. Castro-de-Araujo LFS, Machado DB. Impact of COVID-19 on mental health in a Low and middle-income country. Ciênc saúde coletiva. 2020;25(suppl 1):2457-2460. doi:10.1590/ 1413-81232020256.1.10932020

37. Antiporta DA, Bruni A. Emerging mental health challenges, strategies, and opportunities in the context of the COVID-19 pandemic: perspectives from south American decision-makers. Rev Panam Salud Publica. 2020;44:e154. doi:10.26633/RPSP. 2020.154

38. AHF. AIDS Healthcare Foundation, Peru. Published 2020. Accessed September 12, 2020. https://pruebadevihgratis.pe/conoce-ahf/

39. AHF. Wellness Center AHF Peru. Accessed October 29, 2020. https:/www.facebook.com/wellnesscenterahfperu/?hc_ref=ARTJYA_ D4LnA-aoIITZQE5XKUTK4Pe2AXXzTRS4E88dgYesc_M8G cxo2O2Jn4XAmFrw\&fref $=$ nf\&_tn_ $=\mathrm{kCH}-\mathrm{R}$

40. Garcia-Fernandez L, Novoa R, Huaman B, Benites C. Continuo de la atención de personas que viven con VIH y brechas para el logro de las metas 90-90-90 en perú. Rev Peru Med Exp Salud Publica. 2018;35(3):491. doi:10.17843/rpmesp.2018.353.3853

41. Joint United Nations Programme on HIV/AIDS (UNAIDS). Fast-Track Targets. Published online 2014. Accessed March 5, 2020. https://www.unaids.org/sites/default/files/media_asset/ JC2686_WAD2014report_en.pdf

42. Ruiz Pizarro P. Norma Tecnica de Salud Y Atención Integral Del Adulto Con Infección Del Adulto Con El Virus de Inmunodeficiencia Humana (VIH). Ministerio de Salud; 2018.

43. Peru, Ministerio de Salud. SITUACIÓN DEL VIH EN EL PERÚ IMPACTO Y ESTRATEGIAS FRENTE A COVID-19; Dirección de Prevención y Control de ITS/VIH y hepatitis, 23 de Octubre de 2020. Published online October 23, 2020 . 